\title{
Arquivos, filmes de família e autobiografia em Santiago (2007), de João Moreira Salles
}

\author{
Luíza Alvim \& Jean Costa*
}

\author{
Santiago: uma reflexão sobre o material bruto (Brasil, 2007, 79 min.) \\ Realizador: João Moreira Salles \\ Produção: Maurício Andrade Ramos \\ Entrevistas: João Moreira Salles e Márcia Ramalho \\ Diretor de fotografia: Walter Carvalho \\ Som: Jorge Saldanha \\ Montagem: Eduardo Escorel e Lívia Serpa
}

Se existem imagens demais, é no momento de inseri-las em um texto, em uma reflexão, que elas passam efetivamente a existir. É no momento em que perturbam o lugar de onde vêm e o lugar de quem as criou que elas afirmam suas potências - ser, não ser, ser outra coisa.

(Cezar Migliorin, Sob o risco das imagens: a cena na cena)

A princípio, Santiago foi concebido e filmado para ser um documentário sobre o mordomo da família Salles, ou seja, uma biografia, gênero comum no documentário brasileiro contemporâneo. A filmagem se deu em 1992 e o material continha imagens da antiga casa da família na Gávea (hoje, atual Instituto Moreira Salles - IMS), entrevistas com o mordomo Santiago no apartamento em que este passou a morar e imagens produzidas pelo diretor baseando-se em histórias contadas pelo mordomo.

No entanto, ao se deparar com o material filmado na mesa de montagem, João Salles percebeu que não poderia montar o filme que pretendia. Segundo o diretor, ele não conseguia encontrar o fio narrativo daquelas imagens, abandonando, assim, o filme. Treze anos depois, Salles retoma o material. Santiago se torna, então, um documentário de imagens de arquivo, de um arquivo pensado para ser um filme: é uma reflexão sobre o material bruto, como indica

* Luíza Alvim: Pós-doutoranda. Universidade Federal do Rio de Janeiro - UFRJ, Escola de Música, Programa de Pós-graduação em Música. 20021-290 , Rio de Janeiro, Brasil. E-mail: luizabeatriz@yahoo.com

Jean Costa: Mestrando. Universidade Federal do Rio de Janeiro - UFRJ, Instituto de História, Programa de Pós-graduação em História Social. 20051-070, Rio de Janeiro, Brasil. E-mail: jeancpcosta@gmail.com 
seu subtítulo. ${ }^{1}$ É o trabalho com os arquivos que permite a Santiago existir enquanto filme.

Nesse processo de retomada das imagens, o diretor se dá conta de que o filme contém a memória não só de seu protagonista, como a sua própria e a de sua família. A proximidade inevitável entre João e Santiago, ou seja, do diretor e do sujeito documentado, dando saída a memórias comuns, faz-nos pensar se, de certo modo, Santiago não teria um caráter também de "filme de família" ou, ainda, de autobiografia.

Pretendemos, portanto, questionar o quanto o filme Santiago se aproximaria das seguintes categorias: filme de arquivo, filme de família e autobiografia.

\section{Arquivos: passado, presente e reemprego de imagens}

O uso de imagens de arquivo tem adquirido uma grande projeção no cenário contemporâneo e sua manipulação tem apresentado diferentes formas de se lidar com o passado e sua relação com o presente. Estamos em um momento da História em que somos, definitivamente, "seduzidos pela memória", parafraseando Andreas Huyssen (2000).

Para Anita Leandro (2009), a imagem de arquivo pode ser inserida como um personagem à parte, com o qual interage o material filmado na atualidade e, então, "a imagem do passado torna-se um problema do presente e passa a interferir diretamente na qualidade da palavra filmada" (Leandro, 2009: s/ pág.).

Não por acaso, já desde a década de oitenta, o arquivo deixava de ser um elemento ocasional, de exceção, e surgia a possibilidade de serem construídos documentários somente com essas imagens. Foi o caso da série Histoire( $(s)$ du Cinéma (1988-1998), de Jean-Luc Godard, em que a voz over do diretor costura, em conjunto com a montagem, as rupturas, os planos e as sequências de inúmeros filmes importantes para as histórias do cinema. A voz, nesse caso, é, em última instância, o tempo do presente que ressignifica as imagens do passado. De forma semelhante, dá-se o procedimento em Santiago (2007).

Plenas de passado, as filmagens realizadas em 1992 com aquele que havia sido mordomo da família Salles por trinta anos trazem o recalque ${ }^{2}$ de uma narrativa interrompida, revelada não só pela força das imagens, mas também

1. O título original do filme é Santiago (uma reflexão sobre o material bruto). Daqui em diante, utilizaremos apenas Santiago, sem o subtítulo, referindo-se ao filme lançado em 2007.

2. A partir das concepções de Sigmund Freud, compreendemos o termo recalque como o ato de fazer recuar para fora da cena aspectos que podem perturbar ou desequilibrar a consciência, entendendo que, "porque é inconsciente, o mecanismo do recalque conserva o dinamismo das tendências recalcadas" (Freud, 1997: 270). 
pela voz over escrita pelo diretor e falada por seu irmão Fernando Salles, marca do presente.

No filme, as relações entre passado e presente estabelecem uma conjuntura temporal que ultrapassa a cronologia da modernidade, expondo a necessidade do durar, sem, no entanto, quantificar essa duração. Para Francisco Elinaldo Teixeira isso é uma marca do documentário brasileiro contemporâneo.

Até recentemente, o documentário clássico era visto conforme aqueles traços genéricos que o opunham ao cinema de ficção, quase sem nenhuma especificidade a mais, a não ser o mero reclamo por uma realidade que se queria distinta dos artifícios da ficção. Com uma mudança cultural bastante notável em relação à temporalidade, de algumas décadas pra cá a ideia de um tempo cronológico sucessivo (passado, presente, futuro) cedeu suas prerrogativas para uma concepção crônica do tempo, em que passado e presente se constituem mutuamente, de modo coextensivo e simultâneo (Teixeira, 2006: 257).

Entre os materiais que fazem parte de Santiago (2007), observamos que ele contém não só as imagens do filme de 1992 não montado (podendo este ser considerado um arquivo pessoal), como também imagens de Super-8 da família de Salles, enxertos de outros filmes - A roda da fortuna (Vincente Minnelli, 1953) e Era uma vez em Tóquio (Yasushiro Ozu, 1953) - e fonogramas (a ária da ópera $O$ barbeiro de Sevilha, de Rossini, cantada por Lily Pons, lembrança evocada por Santiago de uma noite no Teatro Colón de Buenos Aires), que são importantes para a sua memória e para a do próprio João Moreira Salles.

Todos esses materiais podem ser considerados como arquivos. Cursino e Lins definem o arquivo como "um conjunto de documentos manuscritos, gráficos, fotográficos, fílmicos que é, de modo geral, destinado a permanecer guardado e preservado" (Cursino e Lins, 2010: 87). No caso de filmes de arquivo, essas imagens guardadas são reempregadas de outra maneira.

Seguindo a classificação de Nicole Brenez (2002), o "reemprego" pode ser intertextual, ou seja, apenas "em espírito" (caso, por exemplo, da refilmagem de uma mesma história) ou de reciclagem. Neste último, é o reemprego da coisa em si e nele se situam diversas práticas do audiovisual, desde a confecção de trailers à realização de diferentes versões a partir da montagem de um mesmo material bruto (reciclagens endógenas), até as práticas de foundfootage (reciclagens exógenas). No caso de Santiago, como o próprio subtítulo nos indica, é uma reciclagem endógena a partir de uma "reflexão sobre o material bruto", com alguns enxertos exógenos.

Santiago se inicia com uma música definida pela voz over como uma melodia dolente que deveria começar o filme de 1992, mas a voz confessa que só veio a conhecer depois a peça específica incluída na montagem do filme. Esta 
é a melodia conhecida como Dança dos espíritos abençoados, do segundo ato da ópera Orfeu e Eurídice de Gluck, peça bastante tocada pelo pianista Nelson Freire em seus bis de recitais e que foi utilizada no filme Nelson Freire (2002), de João Salles. Foi provavelmente só depois disso que o diretor a escolheu como música de abertura de Santiago. Portanto, já no início do documentário, temos um arquivo da própria memória de João Salles, de sua trajetória profissional.

Enquanto ouvimos a música, um movimento lento da câmera nos apresenta três fotografias com as quais João Salles gostaria de ter começado o filme de 1992: a casa da Gávea, o quarto do diretor e uma cadeira solitária na varanda. O caráter dolente que a voz over identifica na música combina com o vazio que se sente nessas fotografias: uma casa, com seus móveis, sem as pessoas que a habitavam. Este começo de filme com as três fotografias, por si só arquivos de um tempo que não volta mais, já diz muito do tema da memória e do esquecimento em um filme feito somente com imagens já prontas. Como ao se remexer em um baú de objetos guardados, com pouco mais de 9 minutos de filme, vemos novamente o plano da primeira fotografia, enquanto a voz over diz que o diretor passou treze anos sem mexer naquelas imagens.

Por outro lado, os planos seguintes aos das três fotos denunciam a miseen-scène ${ }^{3}$ nelas contida: enquanto a voz over fala que nos planos iniciais deveriam figurar somente os objetos cênicos, a imagem joga com o oposto, apresentando parte da equipe em sua composição. A voz over se coloca como dispositivo ${ }^{4}$ de problematização e suspeita sobre o método utilizado por Salles, presentificando o passado tanto das imagens quanto da relação que o documentarista estabelece com elas.

Na primeira imagem do personagem Santiago, este aparece com sua máquina de escrever. Em um mundo cada vez mais acelerado, pautado pelo curto prazo e pela velocidade, Santiago permanecia em seu apartamento como uma espécie de protetor da memória e dos vestígios. Por mais de cinquenta anos, como um copista da Idade Média, tal como a si próprio define, Santiago inventariou a aristocracia da humanidade através de seus escritos sobre a nobreza europeia e construiu sentidos para sua existência a partir de propósitos aparentemente sem razão e sem função. Ele mesmo, num filme só com imagens do passado, é o "homem-arquivo", com suas 30.000 páginas empilhadas.

3. Compreendemos a mise-en-scène como "o modo pelo qual a encenação é disposta na tomada, levando-se em conta os diversos aspectos materiais que compõem a cena e sua futura disposição narrativa (em planos)" (Ramos, 2012: 17).

4. Usamos aqui a palavra dispositivo no sentido dado pelo documentarista Eduardo Coutinho, referindo-se a seus procedimentos de filmagem. "O dispositivo é criado antes do filme e pode ser: filmar dez anos, filmar só gente de costas, enfim, pode ser um dispositivo ruim, mas é o que importa em um documentário" (Lins, 2004: 140, grifo da autora). 
Com efeito, João Salles filma várias vezes o personagem Santiago junto às suas pilhas de papeis, colocadas estrategicamente embaixo do relógio que, tal qual observa o próprio Santiago, "os conserva ativos" e "lhes dá vida", como se desse corda a suas histórias e, deste modo, salvasse a todos do esquecimento.

Em um dos primeiros planos dessas páginas dos arquivos de Santiago, a voz over lê "redenção", "memória", "perene", "contingente", como se anunciasse os temas que perpassam todo o filme. Mais adiante, Santiago explica que sua boa memória é conservada justamente ao escrever seus arquivos. Memória e redenção, memória e esquecimento são, assim, pares indissociáveis. A voz over comenta que "Santiago passou a vida lutando para que seus personagens não fossem esquecidos" e, ao mesmo tempo, o protagonista faz uma observação espirituosa que "estão preparando o seu embalsamento" com as filmagens: o filme de João Salles faria com Santiago, segundo ele, o que o próprio teria feito com seus "mortos".

A aproximadamente oito minutos de filme, Salles nos apresenta o que seria a única sequência mantida por completo de sua primeira montagem. Nela, o time code fica exposto como se afirmasse que "o tempo, além de uma experiência que dura, é uma medida com a qual não se negocia" (Feldman, 2012: 28), ele passa e nada podemos fazer quanto a isso.

\section{Santiago: filme de família?}

Dentre todas as imagens de arquivo presentes em Santiago, destacam-se os planos em Super-8 da família de João Salles à piscina, pois, com exceção do trecho do musical americano $A$ roda da fortuna, são os únicos planos coloridos do filme. Neles, vemos o casal, dois dos filhos, duas empregadas. Sua textura e outras características nos levam a classificar essas imagens como pertencentes a um "filme de família".

O mordomo Santiago não está nas imagens mas, ao mesmo tempo, não deixa de estar: a voz over dissera pouco antes que a memória que Salles tem de Santiago se confunde com a memória da casa da Gávea. É por isso que não estranhamos ao vê-las no filme sobre o mordomo e talvez seja esta também a razão pela qual tendemos, por vezes, a nos questionar se o documentário como um todo não estaria também próximo a essa categoria de "filme de família", embora não tenha sido produzido como tal e a aproximação só possa ser feita posteriormente, a partir de um determinado viés, como veremos.

Roger Odin (1995) define o filme de família como aquele "realizado por um membro de uma família, a propósito de personagens, de acontecimentos ou de objetos ligados, de uma forma ou de outra, à história dessa família e de 
uso privilegiado pelos membros dessa família" (Odin, 1995: 27). ${ }^{5}$ Ou seja, o filme de família funciona como um álbum de fotografias em movimento que só se mostra na privacidade. Odin (1995) também esclarece que o filme de família é uma forma de produto não profissional.

Santiago (2007) não se enquadra nessa moldura. Trata-se de um filme feito por um cineasta profissional já consagrado com o objetivo de ser exibido em festivais e salas de cinema de circuito. Porém, Odin (1995) nos propõe uma outra característica a ser considerada para se classificar um filme como sendo de família. Tal característica seria a de desencadear produções mentais de sentido e de afetos que estão para além do que se mostra nas imagens, de "colocar em movimento nosso cinema interior" (Odin, 1995: 33). ${ }^{6}$ Poderíamos considerar o filme de família não apenas como uma forma ou gênero cinematográfico com determinadas particularidades, mas também como um modo de se relacionar com imagens, mesmo que não digam necessariamente respeito a nós mesmos e às nossas famílias.

Assim, as imagens anódinas da família e das empregadas de João Moreira Salles na sequência em Super 8, para além das características elencadas por Odin (1995) correspondentes ao que se chama de "filme de família" (como a falta de um eixo narrativo, temporalidade indeterminada, imagens borradas, sem maior preocupação com o enquadramento), mostram-nos relações de poder: a família de classe alta à beira da piscina, servida por empregados de uniforme. Mesmo sem estar ali, o mordomo Santiago se enquadra nessa mesma lógica e é ela que rege o filme de 2007. A voz over nos torna claro esse aspecto: "durante os cinco dias de filmagem, eu nunca deixei de ser o filho do dono da casa. E ele nunca deixou de ser o nosso mordomo".

Em 1992, em vez de deixar Santiago falar e desenvolver sua personalidade diante da câmera, Salles reproduziu as determinações de uma relação de classe. $\mathrm{O}$ autoritarismo na direção da performance de Santiago, que observamos no filme de 2007, mostra claramente uma relação de poder entre Salles e o exmordomo. Uma relação que o diretor colocou fora de campo no primeiro filme, mas que agora fica clara: Santiago trabalhou para a família Salles e é, então, impossível apagar a relação de empregado e patrão existente na vida dos dois.

Outro ponto é que, no Santiago de 2007, embora as entrevistas do exmordomo em seu apartamento sejam partes essenciais, a casa da Gávea começa o filme: ela é central neste último. Suas imagens, mesmo sem a presença

5. Tradução livre do extrato: "réalisé par un membre d'une famille à propos de personnages, d'événements ou d'objets liés d'une façon ou d'une autre à l'histoire de cette famille et à usage privilégié des membres de cette famille".

6. Tradução livre do extrato : "mettre en mouvement notre cinéma intérieur". 
imagética dos membros da família Salles, contêm a sua presença fantasmática por seus corredores e salões.

É importante levar em conta que quando Odin (1995) se reporta à "produção mental fantasmática" desencadeada pelo filme de família, ele a compara com a visualização mais restrita à construção narrativa programada do filme de ficção. Porém, Santiago é um documentário e filmes de família têm também aspectos documentais. Esquenazi (1995) considera a contiguidade do "efeito de filme de família" com o "efeito documentário", podendo este último ser considerado como "um efeito 'filme de família' enfraquecido, ou generalizado" (Esquenazi, 1995: 212). ${ }^{7}$ De fato, no filme documentário, há espaço para o "ordinário tornado extraordinário de tal forma que surge por meio da cena das relações cotidianas uma outra cena, aquela na qual o sonho, o acaso, o inconsciente podem ganhar forma e significação" (Comolli, 2008: 156-157).

Porém, ao usar o termo "efeito", Esquenazi (1995) se refere principalmente ao efeito produzido pela recepção de um filme tal como "filme de família" por parte de pessoas que vivenciaram um determinado acontecimento sugerido pelas imagens. Mas, podemos alargar o sentido de "efeito" a propósito das imagens em Super 8 e da casa da Gávea presentes em Santiago: elas proporcionam, mesmo no espectador comum, um "efeito" de se estar assistindo a um filme da família dos Moreira Salles, mesmo que o filme como um todo não possa ser classificado como tal.

\section{(Auto)biografia: um filme de Salles ou sobre Salles?}

No cenário brasileiro da década de 1990 ou da chamada "Retomada", foram se tornando cada vez mais comuns documentários biográficos, em especial sobre personalidades do meio musical. O próprio João Salles dirigiu, em 2003, o filme Nelson Freire, sobre o pianista brasileiro.

Entendemos a biografia como um gênero que, em sua construção, atravessou as reviravoltas da história e se tornou "(...) com o passar do tempo, um discurso de autenticidade, remetendo à intenção de verdade por parte do biógrafo" (Dosse, 2009: 12). François Dosse reflete também que "os tempos atuais são mais sensíveis às manifestações da singularidade, que legitimam não apenas a retomada de interesse pela biografia como a transformação do gênero num sentido mais reflexivo" (2009: 229).

Nessa perspectiva, Santiago (2007) parece expressar justamente uma nova forma de configuração do fazer documental brasileiro contemporâneo, mais próximo da década de 2000. Concebido inicialmente como uma biografia do

7. "un effet 'film de famille' affaibli, ou généralisé." 
ex-mordomo da família Salles em 1992, o filme poderia ser compreendido também como uma autobiografia de João Salles, quando finalizado em 2007.

No texto "O pacto autobiográfico", o teórico francês Philippe Lejeune define a autobiografia como "narrativa retrospectiva em prosa que uma pessoa real faz de sua própria existência, quando focaliza sua história individual, em particular a história de sua personalidade" (Lejeune, 2008: 14) e nesta narrativa deve haver "relação de identidade entre o autor, o narrador e o personagem" (Lejeune, 2008: 15).

Nesse sentido, por documentário autobiográfico compreendemos os filmes cujo narrador é também um dos protagonistas e cuja narrativa está centrada em um processo de busca e reflexão sobre alguma questão importante para sua própria vida. Além disso, é comum nesse tipo de filme o uso de uma linguagem cinematográfica mais poética, ligada à leitura de cartas, ao uso de material familiar e de arquivo e a uma voz over mais intimista, pessoal e confessional. De maneira geral, os documentários autobiográficos trabalham no limiar da estética documental e da ficção, ao passo que lidam com as sobras, as faltas e as reinvenções da memória sob o risco do narcisismo relativo à subjetividade. Para Julieta Roitman

(...) os dois riscos presentes nos documentários subjetivos são, por um lado, a ameaça do narcisismo e, por outro lado, a do fracasso, trabalhando as impossibilidades como ponto de partida: impossibilidade de se lembrar de tudo, de se representar, de lidar com suas perdas, de se encarar como personagem. $\mathrm{O}$ autor, para o bem ou para o mal, é o centro de referência e questão desses filmes, e se mostra a partir de sua própria experiência de autorreflexão (Roitman, 2007:13).

Em 1992, no entanto, eram justamente os traços pessoais do autor que Salles tentava apagar ao filmar o ex-mordomo Santiago. O diretor utilizava como dispositivos o afastamento e o total controle de seu personagem tanto no que diz respeito ao aspecto físico, já que Salles não apareceria na entrevista, e Santiago tinha sua movimentação limitada pelos enquadramentos precisos da câmera, quanto ao aspecto afetivo. Essa atitude fica evidenciada, no filme de 2007, pelos pedidos feitos por Salles ao ex-mordomo para que este não fale como se o conhecesse. Santiago, no entanto, esquecia-se, por vezes, das orientações do diretor, como quando o chama de "Maravilhoso Joãozinho", revelando uma relação de afeto, sentimento e impressões que são da ordem do involuntário.

Ao retomar os arquivos em 2005, já havendo Santiago falecido, Salles revê tudo que havia filmado e, como se as imagens se mostrassem de forma diferente ao diretor, ele percebe uma possibilidade de montagem que 13 anos antes não poderia ter compreendido: e se ele, João Salles, se colocasse como per- 
sonagem da vida de Santiago e vice-versa? Salles era essencial para a composição daquela história, ao passo que a narrativa da vida de Santiago não se compunha apenas de afetos, mas também das relações hierárquicas existentes entre ele e as famílias às quais serviu. Os retaques convocam, então, no filme de 2007, tudo que poderia ser genuíno, involuntário e próprio de Santiago e, ao mesmo tempo, demonstram o autoritarismo e o extremo controle do diretor durante as filmagens.

Salles não era somente um documentarista e Santiago não era somente um mordomo. Sempre houve uma hierarquia que dominava e eliminava as falas de Santiago sob a autoridade da voz de alguém que não era somente o diretor do filme, mas também o ex-patrão daquele personagem. As relações de poder são ainda reforçadas, ao passo que "aquele ou aquela que empunha a câmera detém um poder inquestionável sobre aqueles ou aquelas que são objeto de sua mirada" (Freire, 2012: 30). Romper, portanto, as ligações hierárquicas e afetivas impedia a produção de uma narrativa que fizesse justiça aos dois personagens que ali se encontravam.

Por outro lado, também durante esse intervalo de 13 anos, tanto João Moreira Salles quanto o documentário brasileiro se transformaram. Em 1992, Salles, embora já com alguns trabalhos como roteirista e diretor de documentário, não era ainda um documentarista consagrado. Os trabalhos que o deixaram mais famoso vieram todos depois: Notícias de uma guerra particular (1999), dirigido em parceira com Kátia Lund, e, principalmente, Nelson Freire (2002) e Entreatos (2004), em que já explorava elementos que entrariam na composição de Santiago (2007).

Em 2007, o filme busca mais que a autenticidade da expressão de Santiago, ele busca entender a própria formação pessoal de Salles, "na forma de uma melancolia que extravasa para a própria recordação da mansão da família e do mundo de glórias que abrigou" (Ramos, 2012: 40). Santiago (2007) incorporou a própria mudança no documentário brasileiro alavancada, segundo Ramos (2012), nos filmes de Eduardo Coutinho ${ }^{8}$ a partir dos anos 1990, que exploram "com uma posição recuada do sujeito-da-câmera, o tipo/personagem, fazendo girar a corda da fala" (Ramos, 2012: 41) sem, no entanto, deixar de dialogar com documentários brasileiros autobiográficos lançados poucos anos antes, como Um passaporte húngaro (Sandra Kogut, 2003) e 33 (Kiko Goifman, 2003).

8. A evocação de Eduardo Coutinho é mais do que o reconhecimento de um marco no documentário brasileiro contemporâneo. Também Coutinho realizou, em 1984, Cabra marcado para morrer, um documentário em que retoma imagens de um filme ficcional que iniciou vinte anos antes. Diferentemente de João Salles, no caso de Coutinho foi a situação política do país que tornou impossível a continuação de seu primeiro filme. De qualquer modo, ao retomar as imagens em 1984, Coutinho e o material já são necessariamente outros. 
Assim, o filme de João Moreira Salles deixa de ser uma biografia do mordomo Santiago guiada por suas entrevistas e lembranças, e passa a ganhar elementos autobiográficos mais evidentes, como uma voz over em primeira pessoa representando a voz do diretor, apesar de ser lida por seu irmão Fernando Salles. Por um lado, a voz em primeira pessoa leva à associação imediata à pessoa do diretor do filme, João Moreira Salles. Por outro, a escolha do irmão como fonte dessa voz-eu mostra uma das bases da narrativa que conduz o filme: a dúvida, a suspeita. Em entrevista ao jornal Folha de São Paulo, Salles explica:

Um dos assuntos do filme é a fronteira entre ficção e documentário. A minha voz dava uma concretude muito grande a ele. Com a voz do Fernando, acrescento uma dimensão a mais de ficção no filme. Sou eu falando, mas não é minha voz. É como se introduzisse um espelho a mais, uma camada adicional de desconfiança, de ambiguidade (Arantes, 2007).

Ao convocar a voz de outro para substituí-lo, Salles reforça, sim, mais uma camada de ambiguidade no filme, entretanto, ele não tira da família Salles o espaço da fala sobre as relações hierárquicas e afetivas com o mordomo. Seja por meio das falas de Santiago, seja pela voz que substitui o dono da palavra, Santiago (2007) é realizado por meio de uma "escrita colaborativa", uma vertente da autobiografia em que "o esforço da memória e o esforço da escrita são assegurados por pessoas diferentes" (Freire, 2003: 21).

Com o desenvolvimento da linguagem documental, cada vez mais é possível identificar no cinema contemporâneo esse tipo de estratégia de complexificação do uso da narrativa em voz over. Se até pouco tempo esse artifício era negado por se remeter àquilo que Jean-Claude Bernardet (1985) identificou como a voz do saber, que manipula e retira do outro a palavra sobre si mesmo, cresce hoje uma vertente do documentário que busca na voz over uma outra forma de escrita do mundo histórico, mais ligada à expressão e à busca de si próprio.

Com uma voz que se preocupa menos em relatar a experiência do outro e mais as reflexões sobre a trajetória de vida dos próprios diretores sem se esquecer, no entanto, dos indícios da janela da identificação cinematográfica (Xavier, 2005), os documentários contemporâneos tem cada vez mais sido marcados pela primeira pessoa e, consequentemente, pela expressão da subjetividade dos diretores, tomando um caráter autobiográfico como é possível ver em Santiago (2007).

Para Bill Nichols, "os documentários expositivos dependem muito de uma lógica informativa transmitida verbalmente. Numa inversão da ênfase tradicional do cinema, as imagens desempenham papel secundário" (2005: 143). Todavia, a voz em primeira pessoa nos documentários autobiográficos propõe 
um estilo diferente na escrita da narrativa documental. O comentário em voz over, nesse caso, não tem como papel descrever a imagem nem se sobrepor a ela, esvaziando a pluralidade de sentidos e possibilidades estéticas presentes em sua construção. A palavra não sincronizada à imagem possibilita acrescentar ideias ao campo visual, construir ao menos duas camadas interdependentes para se entender a construção da narrativa documental.

Em Santiago (2007), é também interessante como a voz over, se pensada de forma orgânica, é marca de um ciclo de formação, mostrando-nos que aquele que deveria ser o primeiro documentário de Salles se torna, na verdade, seu filme de descanso como diretor, já que depois de Santiago Salles não dirigiu mais nenhum filme. ${ }^{9}$ É como se todos os filmes e experiências que existiram nesse período, entre a primeira tentativa de montagem de Santiago e o corte final do filme, fossem necessários para que Salles conseguisse finalizar seu primeiro documentário. Cada uma das experiências só toma seu completo valor quando, ao fim, colabora para aquilo que desde o princípio precisava ser feito.

Muitas das escolhas estéticas, técnicas e de elementos culturais apropriadas por Salles em Santigo (2007) são, ou referências já utilizadas por ele em algum filme anterior, ou referências do gosto do mordomo Santiago. Ao fim e ao cabo, são experiências que se prolongam e se transformam, como que em uma viagem. O filme A roda da fortuna e o fonograma da ária do Barbeiro de Sevilha são apresentados após serem nomeados por Santiago; o trecho de Ozu no pós-escrito do documentário é uma referência de João Salles e é um filme que discute o respeito aos mais velhos, a sua memória e o seu esquecimento; a Dança dos Espíritos Abençoados, de Gluck, já fora utilizada em Nelson Freire (2003).

Em certa medida é possível, então, identificar em Santiago (2007) características do que na literatura foi chamado de romance de formação. Lejeune (2008: 42) indaga: "Qual seria essa verdade da qual o romance permite chegar mais perto, senão a verdade pessoal, individual, íntima, do autor, isto é, aquilo que todo projeto autobiográfico visa?". Para Gatti,

Se pensarmos o romance de formação como uma forma orgânica, ou mesmo como uma forma simbólica no sentido dos primeiros românticos alemães, em que os diversos episódios se conectam na composição de um todo, notamos que cada episódio não possui um sentido, ou melhor, uma necessidade nele

9. Santiago (2007) foi o último documentário dirigido por João Moreira Salles do início ao fim. Desde 2007, ele tem se dedicado mais à revista Piauí, criada e editada por ele. Recentemente, ele assumiu, juntamente à montadora Jordana Berg, a fase de finalização do filme póstumo de Eduardo Coutinho Últimas conversas (2015), no entanto, a direção do filme permanece com o nome do falecido diretor. 
mesmo. São elementos casuais que adquirem sentido ao compor uma unidade maior, representada pela trajetória formativa de um herói (Gatti, 2014).

O compartilhamento de memórias com Santiago é um elemento também importante para a composição do caráter autobiográfico desse documentário. Aos dez minutos de filme, a voz over revela que, certa vez, quando os pais saíram para jantar, Salles vira Santiago tocando Beethoven ao piano, de fraque. A voz se dá conta de que, ao montar o filme de 2005, tem consciência de que essa memória não pertence apenas a Santiago, mas também a si próprio.

Nessa sequência, a revelação é feita ao longo de um travelling à luz do dia do corredor percorrido pelo menino João na noite do passado, em um plano que nos lembra os longos travellings de Alain Resnais em $O$ ano passado em Marienbad (1961), outro filme sobre a memória. A figura do travelling pelos corredores da casa é apresentada novamente quando a voz over diz que retomou o filme por ter tido vontade de retornar à casa. É como se, mais uma vez, retornasse aos corredores da memória.

Para Deleuze, referindo-se a Resnais (mas poderíamos também considerar a mesma observação para Santiago), esses travellings "constroem contínuos, circuitos de velocidade variável" (1990:145). Os contínuos são lençóis de passado, maleáveis, passíveis de transformações, cada uma delas com "uma 'idade interna', e poderemos considerar uma coexistência de lençóis ou de contínuos de idades diferentes" (Deleuze, 1990: 145).

Como observa Taís Marcato:

Por trás do objetivo de João Moreira Salles em registrar e expor seu singular personagem, esconde-se um desejo de reviver suas lembranças da infância, da sua família. Santiago é assim um conector que possibilita ao diretor essa jornada de autoconhecimento e de resgate do passado (Marcato, 2014, não paginado).

Ao retomar essas imagens, João Salles parece, portanto, fazer um esforço constante de retorno à sua experiência pessoal, colocando em relevo aspectos particulares de sua história, de sua personalidade. Todavia, sua memória funciona de outro modo, ele mesmo já é um outro, e a sua forma de lidar com seus esquecimentos, suas lembranças e com a expressão de sua subjetividade é outra também.

\section{Reflexões finais}

Em Santiago (2007), podemos perceber que as imagens se constituem como espaço de experiência ao passo que se compõem de um passado atual, capaz de ser incorporado por Salles no presente, não sendo apenas lembranças do diretor, mas todo um conjunto de experiências alheias, coletivas, que 
o possibilitam refletir sobre aquele tempo (Koselleck, 2006). Para Reinhart Koselleck,

A experiência é o passado atual, aquele no qual acontecimentos foram incorporados e podem ser lembrados. Na experiência se fundem tanto a elaboração racional quanto as formas inconscientes de comportamento, que não estão mais, que não precisam estar mais presentes no conhecimento. Além disso, na experiência de cada um, transmitida por gerações e instituições, sempre está contida e é preservada uma experiência alheia. Neste sentido, também a história é desde sempre concebida como conhecimento de experiências alheias (Koselleck, 2006: 309-310).

O trabalho com os arquivos da primeira montagem de Santiago solicita ajuda, então, da memória, pois ele depende daquilo que as imagens do passado evocam, das experiências físicas e afetivas da memória. Nessa direção, os arquivos propõem uma hibridização entre os processos de escrita da narrativa e de evocação da memória. De forma complementar, a expectativa assume um espaço importante ao se trabalhar com as imagens de arquivo, pois, ao passo que ela indica o futuro, lida com as possibilidades das experiências acumuladas naquelas imagens. Nesse sentido, experiência e expectativa completam um ciclo de pensamento não só sobre o tempo que atravessa as imagens, mas também daquele que atravessa a própria história de Salles.

Nessa perspectiva, é o exercício da montagem que dá a esses arquivos a possibilidade de desviar, repensar e restituir as narrativas. Os arquivos evocam memórias que não permitem o esquecimento das narrativas de formação pessoal, pois, enquanto documentos plenos de passado, mostram-nos a possibilidade de rever, reinterpretar e reescrever nossas histórias a partir de processos técnicos e poéticos revelados pela montagem fílmica, "trazendo à tona aspectos recalcados da vida" (Leandro, 2012: 3).

Para Anita Leandro, a montagem é "uma estratégia política de deslocamento das imagens, pois só ela permite tirar as imagens do lugar onde se encontram, confiscadas, e trazê-las de volta à vida, ao espaço da confrontação" (Leandro, 2012: 3). Dessa forma, a montagem se torna um processo que conjuga escolha, ritmo, tempo, olhar e atenção, apresentando o cinema não só como crítica da realidade e da virtualização dessa realidade, mas também como processo de reescrita de histórias particulares, do cotidiano.

A montagem pode ser também pensada, então, como elemento da operação que atravessa espaço de experiência e horizonte de expectativa do material com que se trabalha, pois, assim como é feito em Santiago, ela convoca aquilo que era tido como matéria morta, esquecida, dando uma nova chance ao acúmulo de experiências que possui aquele arquivo e explorando suas potencialidades, seu horizonte de expectativas. 
Muito importante nesse processo é a voz em primeira pessoa, tanto do entrevistado Santiago, quanto a voz over de Fernando Salles com as palavras de seu irmão João Salles. Diretor e personagem contribuem, assim, com seus testemunhos sobre a narrativa da relação entre eles, com suas lembranças e esquecimentos, faltas e excessos, de forma a compor aquele documentário autobiográfico. Segundo Paul Ricoeur,

Uma história descreve uma sequência de ações e de experiências feitas por um certo número de personagens, quer reais, quer imaginários. Esses personagens são representados em situações que mudam ou a cuja mudança reagem. Por sua vez, essas mudanças revelam aspectos ocultos da situação e das personagens e engendram uma nova prova (predicament) que apela para o pensamento, para a ação ou para ambos. A resposta a essa prova conduz a história à sua conclusão (Ricoeur, 1994: 214).

Seja por sua característica de ser feito a partir de arquivos, seja pelas aproximações com o filme de família ou às qualidades de biografia e autobiografia, em Santiago, o tempo que atravessa as imagens, juntamente à sua montagem, é o elemento que possibilita a multiplicidade de narrativas. O material bruto de Santiago, enquanto arquivo, é lugar de memória. A partir do momento em que Salles se debruça sobre aquele material, ele lê não somente as imagens produzidas, mas todo o processo de produção dessas imagens que compõe também seu processo de formação enquanto cineasta.

Essa nova leitura de imagens apresenta ao diretor traços do passado e traços de ruptura com esse passado. Ao mesmo tempo, evoca memórias, que demandam de Salles uma ação sobre aqueles arquivos. Dialogando novamente com Philippe Lejeune, "não posso pedir ao cinema para mostrar o que foi meu passado - minha infância, minha juventude -, posso apenas evocá-lo ou reconstituí-lo" (Lejeune, 2008: 227).

O primeiro filme, o filme não terminado, torna-se, então, o filme da pausa, o filme em que se expressa claramente, seja pela estética, seja pela nova relação ética apresentada por Salles com Santiago, o acúmulo de experiências, o romance de formação do diretor. Há, assim, um convite pessoal, íntimo e quase que confessional para entender as camadas de ambiguidades presentes não só no filme, mas no próprio cotidiano da casa da Gávea.

Isso é proporcionado pelo tipo de montagem utilizado em Santiago. Ela ressignifica uma narrativa interrompida, mas também deixa que a imagem exponha suas potencialidades, suas relações com o espaço e com a sociedade na qual foi produzida. Isso se dá por meio da narração, cuja pretensão não é "transmitir um acontecimento, pura e simplesmente (como a informação o faz); integra-o à vida do narrador para passá-lo aos ouvintes como experiên- 
cia. Nela ficam impressas as marcas do narrador como os vestígios das mãos do oleiro no vaso da argila" (Benjamim, 2010: 107).

Ao retomar as imagens em Santiago, Salles se coloca sob o risco da subjetividade, o risco da exposição de uma relação hierárquica delicada, mas também explora uma reflexão sobre si, sobre sua própria história enquanto documentarista. O documentário autobiográfico, portanto, coloca-se como um dispositivo interessante de expressão de si, sem, no entanto, impedir a identificação de questões comuns ao cotidiano em geral. Sob o risco da exposição, há também a possibilidade de explorar, dessa forma, narrativas que atravessam imagens no tempo, evocando memórias que permitem a continuidade de histórias e do acúmulo de experiências de formação do sujeito no mundo.

\section{Referências bibliográficas}

Arantes, S. (2007). Após 'Santiago', Salles volta à família. Folha de São Paulo. 24 Agosto. Disponível em: http://www1.folha.uol.com.br/fsp/ilus trad/fq2408200707.htm

Benjamin, W. (2010). Sobre alguns temas em Baudelaire. Obras escolhidas III - Charles Baudelaire um lírico no auge do capitalismo, trad. José Carlos Martins Barbosa e Hemerson Alves Baptista, São Paulo: Brasiliense.

Bernardet, J.-C. (1985). Cineastas e Imagens do Povo. Ed. Brasiliense, São Paulo.

Brenez, N. (2002). Montage intertextuel et formes contemporaines du remploi dans le cinéma expérimental. Cinémas, automne, 13(1-2): 49-67.

Comolli, J.-L. (2008). Ver e poder - A inocência perdida: cinema, televisão, ficção, documentário. Belo Horizonte: Humanitas.

Cursino, A. \& Lins, C. (2010). O tempo do olhar: arquivo em documentários de observação e autobiográficos. Conexão - Comunicação e Cultura (Revista acadêmica do Centro de Ciências da Comunicação da Universidade de Caxias do Sul), 9(12): 87-99.

Deleuze, G. (1990). A imagem-tempo. São Paulo: Brasiliense.

Dosse, F. (2009). O Desafio biográfico - Escrever uma vida. São Paulo: EDUSP.

Esquenazi, J.-P. (1995). L'effet 'filme de famille'. In R. Odin (org.), Le filme de famille : usage privé, usage public. Paris: Meridiens Klincksieck.

Feldman, I. (2012). Jogos de cena: ensaios sobre o documentário brasileiro contemporâneo. São Paulo: Tese de Doutorado, Universidade de São Paulo. 
Freire, M. (2012). Documentário: ética, estética e formas de representação. São Paulo: Annablume.

Freire, M. (2003). Jean Rouch ou o filme documentário como autobiografia. Uma introdução. Estudos Socine de Cinema: 19-26, ano V, São Paulo.

Freud, S. (1997). Recalque. Os Filósofos Através dos Textos: 268-271. São Paulo: Paullus.

Gatti, L. (2014). A montanha mágica como romance de formação. Viso - Cadernos de estética aplicada, (15). Disponível em: http://revistaviso.com. br/pdf/Viso_15_LucianoGatti.pdf.

Huyssen, A. (2000). Seduzidos pela memória. Rio de Janeiro: Aeroplano.

Koselleck, R. (2006). Espaço de experiência e horizonte de expectativas. Futuro passado: contribuição à semântica dos tempos históricos: 311-337. Rio de Janeiro: Contraponto.

Leandro, A. (2009). Estratégias contemporâneas de inclusão da imagem de arquivo no cinema. Anais do XIII Encontro Internacional da Sociedade Brasileira de Estudos de Cinema e Audiovisual (Socine). São Paulo. Disponível em: http://www.socine.org.br/anais/interna.asp?nome=anita\%20 leandro

Leandro, A. (2012). Desvios de imagens, ontem e hoje: de Debord a Coutinho. Anais do XXI Encontro Anual da Compós. Universidade Federal de Juiz de Fora, junho.

Lejeune, P. (2008). O pacto autobiográfico: de Rousseau à Internet. Belo Horizonte: Editora UFMG.

Lins, C. (2009). A voz, o ensaio, o outro. In B. Furtado (Org). Imagem contemporânea: cinema, tv, documentário, fotografia, videoarte, games. São Paulo: Hedra.

Lins, C. (2004). O documentário de Eduardo Coutinho: televisão, cinema e vídeo. Rio de Janeiro: Jorge Zahar.

Marcato, T. (2014). O sujeito no documentário torna-se o sujeito do documentário: um estudo sobre a autobiografia em Santiago. Associação Brasileira de Cinematografia, 4 Abril. Disponível em: http://www.abcine.org. br/artigos/?id=1377\&/o-sujeito-no-documentario-torna-se-o-sujeito-do-d ocumentario-um-estudo-sobre-a-autobiografia-em-santiago

Migliorin, C. (2010). Sob o risco das imagens: a cena na cena. Grumo, 8: 50-55. Buenos Aires.

Nichols, B. (2005). Introdução ao Documentário. Campinas: Papirus. 
Odin, R. (1995). Le film de famille dans l'institution familiale. In R. Odin (Org.), Le filme de famille: usage privé, usage public. Paris: Meridiens Klincksieck.

Ramos, F. (2012). A mise-en-scène do documentário: Eduardo Coutinho e João Moreira Salles. Rebeca, 1:1-38.

Ricoeur, P. (1994). Tempo e Narrativa. Campinas: Papirus.

Roitman, J. (2007). Miragens de si: ensaios autobiográficos no cinema. Rio de Janeiro: Dissertação de Mestrado, Pontifícia Universidade Católica.

Teixeira, F.E. (2006). Documentário moderno. In F. Mascarello (Org.), História do cinema mundial. Campinas: Papirus.

Xavier, I. (2005). O discurso cinematográfico: a opacidade e a transparência. São Paulo: Paz e Terra.

\section{Filmografia}

33 (2003), de Kiko Goifman, Brasil.

A roda da fortuna (1953), de Vincente Minnelli, Estados Unidos. Título original: The Band Wagon.

Cabra marcado para morrer (1984), de Eduardo Coutinho, Brasil.

Entreatos (2004), de João Moreira Salles, Brasil.

Era uma vez em Tóquio (1953), de Yasushiro Ozu, Japão. Título original: Tokyo monogatari.

Histórias(s) do cinema (1988-1998), de Jean-Luc Godard, França. Título original: Histoire( $s)$ du cinema.

Nelson Freire (2002), de João Moreira Salles, Brasil.

Notícias de uma guerra particular (1999), de João Moreira Salles e Kátia Lund, Brasil.

O ano passado em Marienbad (1961), de Alain Resnais, França. Título original: L'année dernière à Marienbad.

Santiago: uma reflexão sobre o material bruto (2007), de João Moreira Salles, Brasil.

Últimas conversas (2015), de Eduardo Coutinho, Brasil.

Um passaporte húngaro (2003), de Sandra Kogut, Brasil. 